able of rolief by our nich bere were considered incapable of rolief by our cham the importance be justly attaches to the subject, it lowe that the apparatus I described is very little known, oc the operation very little now practised in London ; $t$ for ftes otating that " the apparatus first applied was fixed on tho pelvis, and the extension was made with a strap beneath the chin, attached to a bar which paseed behind the spine and arched abore the head," he proceeds to say : "but that eontrivance was scarcely firm enough, and the child therefore slipped her head aside from it ; I therefore resolved on having an instrument to rest on the shoulders, and after Dr. Hillier had kindly searched in vain among the stores of our mechanicians for one likely to accomplish our object, I sent for Mr. Hainsley to construct one; his apparatus has fully answered my purpose." The engraving of the patient, taken two years afterwards, fully shows this; and it is gratifying to me to have this very unbiassed testimony from a surgeon of Mr. Quain's eminence, to the principles of an operation which I believe I am entitled to say, as regards the neck, originated with me.

In the memoir in the Medico-Chirurgical Transactions to which I have alluded, will be found a short history of three cases, with a rough sketch of the apparatus (which has since been improved), and of which an engraving is given in a Memoir published by my late friend Mr. Henry Earle, in the year 1832, in which he did me the honour to commend its use.

In the first case on which I operated, I endeavoured to prevent the recurrence of the contraction, by a power applied to draw back the head, on the same principle as Mr. Quain first adopted, but was baffled, as I believe will ever be the case, from the mobility of the cervical spine eluding the application of the power so employed; I therefore was led to think that it was necessary to have more fixed points d'appiri to counteract this, and these I considered to be the thorax below, and the head above. The success of the apparatus alluded to has since, in many cases which have occurred to my colleagues in this hospital as well as to myself, been complete; it not only preventing a recurrence of the contraction of the soft parts, but, by the gradual operation of the screw, redeeming the abnormal position of the bony structures which the firm tie of the cicatrix, especially when the subject was growing, had produced.

Mr. Quain apprehended, not without reason, that the contraction might return; he therefore did not publish his case until two years had elnpsed, and the permanence of the cure was in all probability ascertained.

I may now mention one case which, from the extreme character of the deformity, as well as from the long period which has elapsed, is still more important. It is that of a young woman from Cornwall, on whom I operated July 2nd, 1842 ; the deformity was fully as great as or more so than in the case delineated by Mr. Quain. The age (twenty-four) offered more difficulty; but the cure was certainly not less perfect, as is proved hy two casts, one taken before, the other after the operation, which are now in our Hospital Museum; these casts I took to Leeds, and showed at the meeting of the Provincial Association in August 1843. They were also seen by my friend Mr. Partridge, on my return through London; and he was so much struck with them, that he had copies taken and placed in the Museum of King's College. I may further add, that being much impressed with the importance of the method, I sent my casts and the apparatus to the Great Exhibition in 1851. Now, as regards this particular case, I am informed by my colleague Mr. Kempe (whose father originally sent the patient to me) that there has been no return of deformity; and I may say the same of another very bad case, Elizabeth Bulley, operated on by me in 1824, whom I myself saw lately.

The apparatus in question is not only useful in giving full effect to the operation for the removal of cicatrices in

+.I may likewise meition that in the three latest works of authority on general surgery by London surgeons, there is no notice +aken of it. I mean bo Bouch, Erichsen, and Druith the neck, but also in preventing their occurrence, if employed before these dense, unyielding structures are fully formed. It is also useful in cases of wry neck, whether to assist the operation, or to obviate the necessity for one; still more it is of the greatest value in cases of disease or injury of the cervical vertebroe, where a steady support to the head is required. In each description of case, I have derived great advantage from its employment; and it is, therefore, not so much for the purpose of showing that I had anticipated Mr. Quain in his views as regards the cure of these vicious cicatrices in the neck- - riews which he arrived at upon the same principles as myself, and without being aware of what I had done-as because it is my anxious endeavour to draw the attention of the profession to its more extensive use in the three other instances now stated.

Mechanical inventions in our art have, I conccive, in modern times, been too lightly esteemed by surgeons. For the most part, such inventions are founded upon as complete a knowledge of anatomy and the principles of surcery as any other branch of surgery, properly so speaking; and while they involve this knowledge to the fullest extent, they also imply readiness in adapting measures to remedy many most important evils. I am not a ware that the Council of the Royal College of Surgeons have adopted any measures calculated to encourage this part of our science; or that, in their vast Museum, any provision is made for the reception and record of instruments and apparatus which might serve mankind-the "Artes qua omnibus prosint," to use their own motto; but it is crident that the power of referring to such a collection would be of great value in many ways, and possibly the subject may receive the attention of the eminent men who form that Council.

July 21 st, $18 v 6$.

\section{CONSIDERATIONS RESPECTING THE OPERATION OF MALARIA ON THE HUMAN BODY.}

By C. Handfied Jones, M.B., F.R.S., Assistant-Physician to St. Mary's Hospital.

Iv the following remarks, I wish to draw attention to a cause of disease well known and appreciated in foreign lands, but in this country less considered than I beliere it ought to be. I refer to malaria; and I would say at once, that I do not mean to restrict the use of the term to the miasma produced by marshy lands, but to permit it a far wider application. What malaria may be in itself, we do not know-whether it be a chemical compound, a peculiar electrical state, or an allotropic form of common uatterbut we may say that it is distinct from the causes of typhus, typhoid, small-pox, or the other exanthemata; that it rather manifests relations of affinity with the causes of screral most common disorders; and that the conditions which give rise to it must be of rery common occurrence.

I proceed to notice briefly some of the most important points in the history of malaria, and then to consider at more length the diseases which it produces.

1. The almost universal prevalence of malaria throughout the temperate and tropical regions of the globe, is a circumstance, it appears to me, of the most striking import. Go almost where we will, to the fairest and brightest spots on the surface of the earth, the same evidence of the pronounced doom ever appears. Still it is found to be the case, "that cursed is the ground for thy sake". What is the country in Europe that is exempt from this scourge? As far north as Sweden it prevails; and the farther we proceed south the more intense and deadly does the poisonous influence become. From all the shores of the Moditerranean, we have accounts of its existence; and in Sicily, one of its islands, a non-medical authority has specified particularly no less than eighty-two unhealthy situations. It was probably one of these that a British com- 
manding officer three or four times attempted to occupy as a telograph post, and did not desist, though warned by the matives of the consequences, until thirty men were successively destrojed by the unseen foe. Of the tertian ferers of Minorca, Cleghorn has written; and of the extermination of their garrisons at St. Fiorenzo, in Corsica, French authorities can tell. In Algeria, the same malaria is met with, as abundantly witnessed by MM. Boudin, Maillot, and Laveran. To attempt any further detail of the places where malaria has been found by sad experience to prevail, would engage me in almost endless quotations and references, and is perfectly needless. We all know by even popular report of the fevers of the Fast and West Indies, the coast of Africa, North and South America, Burmah and China; and the dependence of these on malarious influence is as well ascertained as anything possibly can be. Now, one cannot but conclude from what has been stated, that the conditions which gire rise to malaria must be exceedingly common ones; and that it cannot be regarded as a miasm capable of being evolved only in a few special localities.

2. It is an establishod fact, that the presence of vegetable matter is by no means necessary for the production of malarious discase. Ample proof of this is cited by Dr. Watson in his Lectures, and by Mr. Martin in his work on Tropicul Climates. 'The former adopts the plain conclusion, that, "for producing malaria, it appears to be requisite that there should be a surface capable of absorbing moisture, and that this surface should be flooded and soaked with water, and then dried; and the higher the temperature, and the quicker the drying process, the more plentiful and the more virulent (more virulent, probably because more plentiful) is the poisun that is evolred." And again: "There is reason to believe that the flooding of a porous earthy surface with water, and the subsequent drying of that surface under a certain degree of heat, constitute the sole or main conditious of the generation of the poison." (Watson, page 720.) Nr. Martin is inclined to attribute the malariagenerating property of soils to their containing a quantity of iron ore. He has obtained evidence showing that, at all the most unhealthy stacions on the west coast of Africi, the earth and the mud of the rivers was invariably ferruginous. Similarly in the slave States of North America, it is mentioned by Mr. Featherstonehaugh that malaria is found in continual connexion with the ferruginous soil of those countries, with the red sandstone rock, and the red mud of the Arkinsas. (Martin, p. 26.) Now, must we not really feel that these statements respecting the non-essentiality of vegetable decay to the production of malaria are of the very widest and grarest import? If it be indeed so that the mere rapid eraporation of water from a soil that has been saturated is adequate to generate a deadly poison, where shall we undertake to say that this may not happen? Even should it be necessary that the soil should be ferruginous, how very common still would be the conditions capable of producing malaria! Sowe fragments of medical experience seem to point, however, nearly in the same direction. Dr. A. T. Thomson recommends that the floor of a sick room should be swept-never washed. "An invalid may as well sleep in a swamp as in a room the floor of which is frequently washed." Dr. Alison has observed the frequent occurrence of croup on Saturday night, the only day in the week on which it is customary for the lower orders in Edinburgh to wash their houses. These and like expcricnces may be worth bearing in mind in attempting to form to ourselves a theory of malaria. The production of dysentery by malaria, which no one doubts, and of croup by the vapour from a drying surface, are not thiugs very dissimilar.

3. There seems good reason to believe that a very bricf exposure to malarious emanations is sufficient to affect the system, at least when the poisonous influence is very intense. Dr. McCulloch states that he has frequently observed that fever may be induced within half an hour after exposure to malaria, and that a single inspiration, or the space of a very few seconds, is amply sufficient for the purpose. His experience, he affirms, is corroborated by that of many practised and acute French and Italian physicians. They record instances of labourers dying instantaneously from merely sitting or lying down on the ground, and of others who, from looking into a ditch or drain, have been struck dead by the poison which, of course in a minor degree, would have merely produced a fever. Lind also describes, as well as many others, an instant seizure with nausea and delirium.

4. It is certain that a person may be exposed to malsrious emanations, and jet suffer none of the usual effects until some considerable time, weeks or months after, when some special exciting cause comes into operation, as the setting in of an east wind, exposure to cold and wet, great fatigue. Nay, the malaria may fail to affect the system at all in the absence of these exciting causes, when otherwise it is morally certain that it would have. I must quote a very interesting fact in proof of this from Dr. Copland (Art. Disease, p.571):- " Between twenty and thirty persons were exposed all night without cover to the air of one of the most fatal sources of miasmata furnished by a warm climate, during the unhealthy season, but were soon afterwards removed to sea, far from any further exposure to this specific cause. They continued well for six or seren days, when about half their number experienced great fatigue. All these were nearly simultancously-on the following day-seized with remittent ferer; while those who had not been subjected to the consecutive cause, with the exception of two, who were not attacked till several days subsequently, entirely escaped, although all had been equally exposed to the specific cause of that form of fever." I have now a young female under my care with tertian ague, who lived with her family at Wisbeach, in Cambridgeshire, till she was about fourtecn. Since then she has been living in London, but has not had any ague till the present attack, which is five years from the time of her change of residence. It seems reasonable to suppose that the debilitating influcnces of a town life have brought the original infection into play by impairing the vital resistance. II father had ague when a lad, was then free for a number of years, and healthy. After he came to London, he continued frce for four years, but was then attacked by quotidian.

5. When very intense, the action of malaria on the system is most deadly, prostrating organic life, just as in the worst forms of malignant cholera. This is what has been termed febris algida, the patients never attaining to reaction after the deadly stroke, but dying in the cold stage. In some of these cases, the peril is from a special affection of the heart; but, in the majority, the prostration involves the whole nervous system. As an example of this condition, I quote the following description from M. Bailly. A. G., aged 18 years, of good constitution, was brought to hospital on erening of July 29th. During the night, he complained continually of sharp pains in the belly: the whole of the body was as cold as ice. At 8 A.M. the following morning, the legs, thighs, forearms, arms, cheeks, were of an icy coldness; the belly, chest, and forehead, were of rather a lower temperature than other parts of the body; pulse insensible at the wrist, feebly felt in the crural arteries, 100. The patient trembled and complained continually. His most common position was on the left side, with the thighs drawn up. He understood what questions were put to him, but not sufficiently well to give proper answers; he never entered into any detail, and died at halfpast nine. At the post mortem, there was found most intense congestion of the small and large intestines, amounting in the rectum to hxmorrhagic exudation. The liver was healthy, the spleen enlarged. No other marked morbid appearance. When reaction has set in, the peril is then chiefly from acessive determination of blood to the head, as the following case shows:-B. S., aged 30 years, of strong constitution, affected for some time with tertian fever, admitted July 2nd. On 3rd, had a slight febrile access. On the 4th, towards midday, he walked in the ward, felt very well, and laughed with the other patients. 
Ali of sudden he was seised with violent shivering, to which mccoeded a very high ferer, during which ho ind elternate tension and flexion of the forenrms, and rofound coms. He died in six hours. At the post profound there was found vivid injection of the whole of the mortem, there was found matter of the brain much deeper coloured than natural, approsching a dark reddish grey; a little water in the rentricles; stomach of a deep diffused red, especially towards its great curvature; patches of conrestion in the small intestines, with ascarides collected upon them. Mr. Martin mentions having been attacked by a dangerous remittent ferer in India, from the violence of which he must have speedily sunk but for a profuse hoomorrhage from the nose during the height of the two first paroxysms. These examples, which are but common ones, ghon forcibly what are the effects of the violent, stormy assaults of malaria. But the gradual chronic operation of this poison on the human frame, when it has become to a certain extent habituated to it, is scarcely less striking. Dr. Watson says, "The race of inhabitants deteriorates. Their stature is small; their complexion sallow and yellowish; they are prematurely old and wrinkled; even the children early acquire an aged aspect; and the spirits and intellect of those who dwell in these unhealthy spots are low and feeble, and partake of the degeneration of their bodily qualities." According to Monfalcon, the moral state of the inhabitants of malarious districts is very degraded; crime of a dark dye is common, but still of a mean rather than of a bold character. The term of life is much shortened in such countries, the average in Holland being 25 , and in some districts of France $22,20,18$, instead of about 50 , which it is with us.*

[To be continued.]

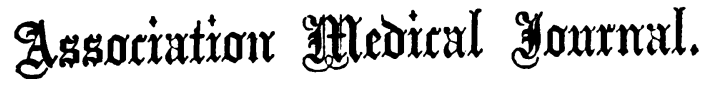

SATURDAT, AUGUST 9TH, 1856.

\section{THE TWENTY-FOURTH ANNUAL MEETING OF THE BRITISH MEDICAL ASSOCIATION.}

THF principles enunciated at the great Birmingham Meeting of Norember last, elaborated into laws, have been discussed, and, with few alterations, passed by the General Meeting of the twenty-fourth annual gathering of our Association. A revolutionary period has been safely passed, and the old Provincial Association comes forth renewed, like old Asson, in the shape of the British Medical Association. That so great a change-a change involving the whole constitution of our body-should have taken place so quietly, and should have left behind it such a good understanding between the conflicting parties, is, we think, the greatest testimony that could be paid to the strength of the associative principle which binds us together, and of the determination of all our members to preserve the one Institution, if we may so term it, which has survived unshaken for an age at least, amid the mutations which have befallen other medical associations. The revolution that we have accomplished, if it had been merely nominal,

- Dr. Macenlloch says:-" The expression keeps pace with all else; being that of unhappiness, stupidity, and apathy; an habitual melanoholy which nothing can rouse, and an insensibility to almost everything which operates on the feelings of mankind in general. $A$ sow and languid opeech, a simin ingrer in the malk, and in all the actions, indicate equally the condition of would have held out no chance of permanency; indeed, it rould only have been the foreshadower of a weries of conrulsions, which could have no other end than the destruction of the Association. We think we may state, without fear of contradiction, that what has been done has: been with the willing consent of all parties, and that no. arrière-pensée exists among us. The two foundations on which we build for the future are, a sound financial condition, and a thoroughly representative government. The reader has only to turn to the Treasurer's Report, to perceive that the great exertions made to clear off the load of debt have been eminently successful. Seven hundred members have responded to the ten-shilling call; and; without doubt, a very large majority of the associates will do so before the end of the year. If all do this, the Treasurer will, by the 1st of January 1857, hold a clear balance in favour of the Association of several hundred pounds. It must, therefore, be considered that the financial difficultythe rock ahead, which heretofore loomed in the distance, and threatened our destruction sooner or later-has been remored from our path, and that we shall shortly be placed in the rery small category of those associations which stand clear of debt.

With respect to our new form of government, it cannot be denied that it is free as air. Every member of the Association, by joining a Branch, has the right of electing to the General Council; and the General Council, thus elected on the wide basis of universal suffrage, elects the Committee of Council, which replaces the old Executive Council. Thus the associates hold in their hands, either directly or indirectly, the entire reins of power ; and the only remnant of the old state of things is the law which provides " that the President of the Council shall be, in the first instance, Sir Charles Hastings permanently", etc. In proposing this law, which was, in fact, a part of the previous written law of the Association, the Laws Committec acted in the spirit of the whole Association; for undoubtedly the gardener who planted twenty-four years ago the tender sapling which has since grown into such a goodly tree, has a right, both by prescription and affection, to watch orer it in the chief place, unmolested and undisputed, to the last. That, however, which we have not disputed he has generously relinquished, having agreed to place himself in the position of future Presidents of Council, by returning his lease of power into the hands of the General Meeting at the end of three years. This graceful act, so far from weakening the authority of Sir Charles Hastings, will, without doubt, clench it more firmly than ever.

The establishment of a free federal Government, independently of the discontent it will eliminate, will, in our opinion, have the effect of vastly extending the power of the Association, inasmuch as every member must now belong to a Branch before he can have a voice in the representation. This one fact will tend to increase the power of existing Branches, and to establish new ones where they do not now exist. Nothing can be more certain than that the 